\title{
A SEMANA ACADÊMICA DE ENGENHARIA MECÂNICA E DE PRODUÇÃO - SAEMPRO 2016
}

\author{
L. BENINI ${ }^{1}$, A. M. O. SIQUEIRA ${ }^{2}$ \\ ${ }^{1}$ Universidade Federal de Viçosa, Departamento de Engenharia de Produção e Mecânica \\ ${ }^{2}$ Universidade Federal de Viçosa, Departamento de Química \\ E-mail: lucas.benini@ufv.br
}

\begin{abstract}
RESUMO: A Semana Acadêmica de Engenharia Mecânica e de Produção - SAEMPRO é um evento organizado por professores e alunos do curso de Engenharia de Produção $e$ Mecânica da Universidade Federal de Viçosa. A SAEMPRO 2016 contou com o apoio do Departamento de Engenharia de Produção e Mecânica (DEP), do Diretório Acadêmico de Engenharia de Produção (DAEP) e do Programa de Educação Tutorial da Engenharia de Produção (PET-EPR). Neste ano, o evento reuniu em um único período e local, um conjunto de atividades diversas, com base no tripé ensino-pesquisa-extensão, que procurou estimular a capacidade de planejamento e gestão de projetos por parte dos envolvidos, professores e estudante e que permitiu a interação entre alunos de todos os periodos dos cursos, bem como, com egressos e profissionais especializados. Para os estudantes envolvidos na organização, o evento foi uma oportunidade impar pela vivência de problemas, dificuldades e desafios e construção de oportunidades, soluções, relacionados ao campo de atuação dos engenheiro.
\end{abstract}

PALAVRAS-CHAVE: Semana acadêmica; Ensino de engenharia; Engenharia Mecânica; Engenharia de Produção.

\section{INTRODUÇÃ̃O}

Tendo em vista a reestruturação do foco editorial do periódico The Journal of Engineering and Exact Sciences - JCEC, este artigo apresenta o escopo da Semana Acadêmica de Engenharia Mecânica e de Produção - SAEMPRO 2016.

A SAEMPRO e eventos academicos similares representa uma possibilidade "da associação entre ensino, pesquisa e extensão como fator desencadeador do processo de ensino, na perspectiva de rupturas paradigmáticas com a racionalidade técnico- instrumental e geradora de inovações pedagógicas na educação superior, em contraposição ao modelo acadêmico vigente" (MAZZILLI, 2011).

A SAEMPRO surgiu através da união de dois outros eventos acadêmicos da UFV, a SAEM (Semana Acadêmica de Engenharia Mecânica) e o SAEPRO (Simpósio Acadêmico de Engenharia de Produção). O evento tem por objetivo trazer conhecimentos teóricos e práticos relevantes à formação dos estudantes de Engenharia Mecânica e de Engenharia de 
Produção, bem como demais engenharias, através das diversas atividades realizadas, entre as quais palestras, apresentação de cases, minicursos e workshops.

A SAEMPRO é um evento organizado por professores e alunos do curso de Engenharia de Produção e Mecânica da Universidade Federal de Viçosa. A Comissão Organizadora da SAEMPRO 2016 contou com o apoio do Departamento de Engenharia de Produção e Mecânica (DEP), do Diretório Acadêmico de Engenharia de Produção (DAEP) e do Programa de Educação Tutorial da Engenharia de Produção (PET-EPR). Neste sentido, o evento reuniu em um único período e local, uma conjunto de atividades diversas, com base no tripé ensino-pesquisa-extensão, que procurou estimular a capacidade de planejamento e gestão de projetos por parte dos envolvidos, professores e estudantes (GONÇALVES, 2015; SOARES, FARIAS e FARIAS, 2010; MOITA e ANDRADE, 2009).

Gonçalves (2015) destaca que o

"princípio da indissociabilidade entre Ensino, Pesquisa e Extensão não pode ser pensado de forma isolada, como fim em si mesmo. Ele decorre de discussões acerca da consolidação de determinado projeto de Universidade, cuja formação e produção de conhecimento dialogassem de forma mais ativa e dialógica com os demais segmentos da sociedade. Assim, esse princípio envolve uma dupla perspectiva sobre sua presença e desenvolvimento na Universidade."

Por sua vez, Pivetta et al.(2010) destacam que:

"Assumir uma atitude inovadora e transformadora da realidade social implica ampliar e fortalecer a integração entre ensino, pesquisa e extensão, enquanto processo formativo sistêmico."

Alinhada a esta concepçãom a idealização da SAEMPRO foi fundamentada na reflexão do futuro engenheiro na sociedade contemporânea. Diante deste cenário definiu-se o tema "Eu, a indústria e o mundo", a partir do qual abordou-se na seção "Eu" a capacitação individual e as oportunidades disponíveis durante a graduação; em "a Indústria", assuntos relacionados aos novos meios de tecnologia, o mercado de trabalho, os desafios nos sistemas produtivos bem como a indústria do futuro; e na última seção "o Mundo", temáticas relativas ao empreendedorismo, a sustentabilidade e a inovação.

\section{O EVENTO}

As atividades de planejamento da SAEMPRO iniciaram seis meses antes da data do evento. Nesse período, os envolvidos, professores e estudantes, formam diferentes equipes de trabalho, de modo a executar com exito a organização das áreas de logística, de marketing, de finanças, de oferta de minicursos, palestras e workshop, para fazer o planejamento das atividades de cada setor.

O evento foi realizado entre os dias 08 e 11 de novembro de 2016 no auditório da Engenharia Florestal no campus Viçosa da UFV e teve nesta primeira edição 192 inscritos. A I SAEMPRO recebeu 50 resumos na forma expandida e 20 resumos na forma simples. Alunos de outras instituições de ensino superior aderiram ao evento: IFMG de Governador Valadares, UNILESTE de Coronel Fabriciano, UNA de Belo Horizonte e UFJS de São João del Rei, dando a SAEMPRO uma abrangência estadual. Além disto, recebeu-se trabalhos de outros departamentos do campus Viçosa da UFV: Departamento de Administração e Contabilidade - DAD e Departamento de Engenharia Elétrica - DEL. A programação do 
evento é apresentada na Figura 1.

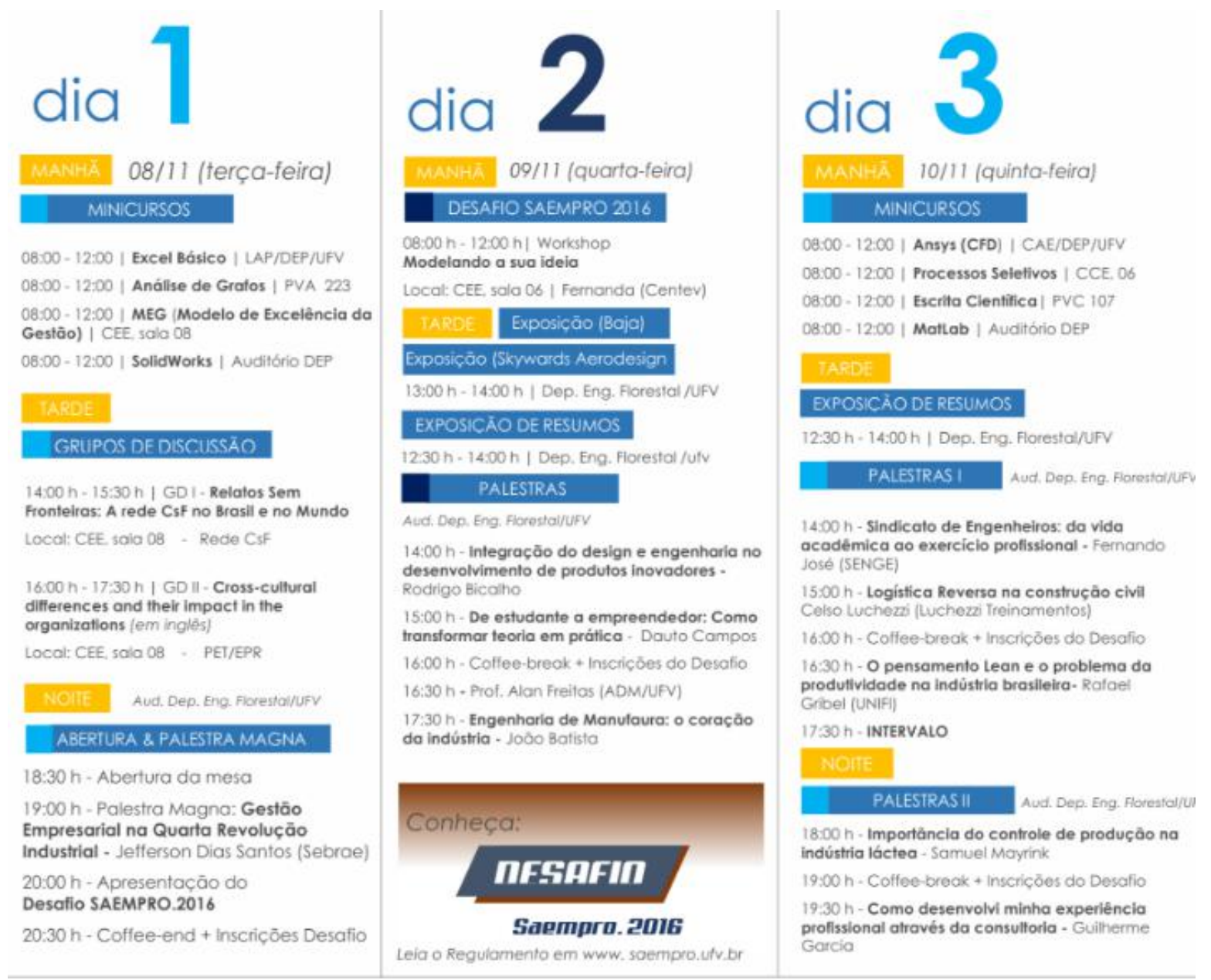

Figura 1 - Programação da SAEMPRO 2016.

Foram oferecidos 12 minicursos no evento: Excel Básico, Análise de Grafos, MEG (Modelo de Excelência da Gestão), SolidWorks, Ansys (CFD), Processos Seletivos, Escrita Científica, Matlab, Gestão de Estoques, Ansys Estrutural, LabView e Workshop: Diálogo sobre carreira e mercado de trabalho. A maioria destes minicursos foram ministrados por docentes e discentes da própria UFV. A Figura 2 apresenta fotos referentes a quatro minicursos ofertados no evento.

Destaca-se que a inscrição para participar de qualquer minicurso consistiu em um litro de leite e que a quantidade arrecadada foi posteriormente doada para a instituição filantrópica, de caráter assistencial, sem fins lucrativos, "Lar dos Velhinhos de Viçosa".

Teve-se a participação de palestrantes de várias instituições, como Centev, Luchezzi Treinamentos, Votorantim, UNIFI, SENGE e LATAM (Figura 3), além da palestra magna "Gestão empresarial na quarta revolução industrial" sob responsabilidade do SEBRAE. Ademais, alunos membros dos projetos de extensão (BAJA e Aerodesing) e da empresa júnior (Soluções Consultoria) vinculados ao Departamento de Engenharia de Produção e Mecânica - DEP apresentaram seus principais resultados aos participantes da SAEMPRO. 


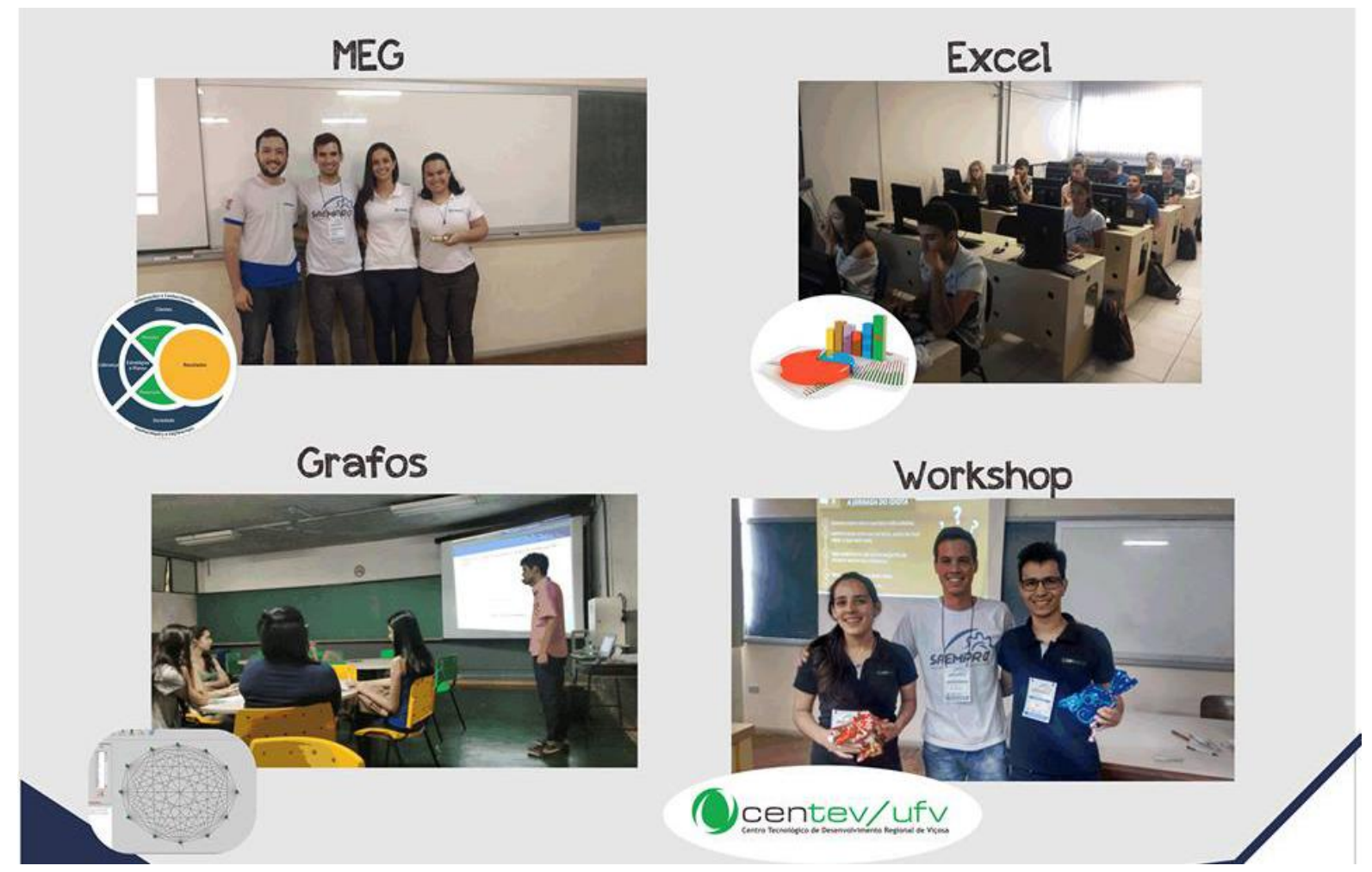

Figura 2 - Minicursos da SAEMPRO 2016.

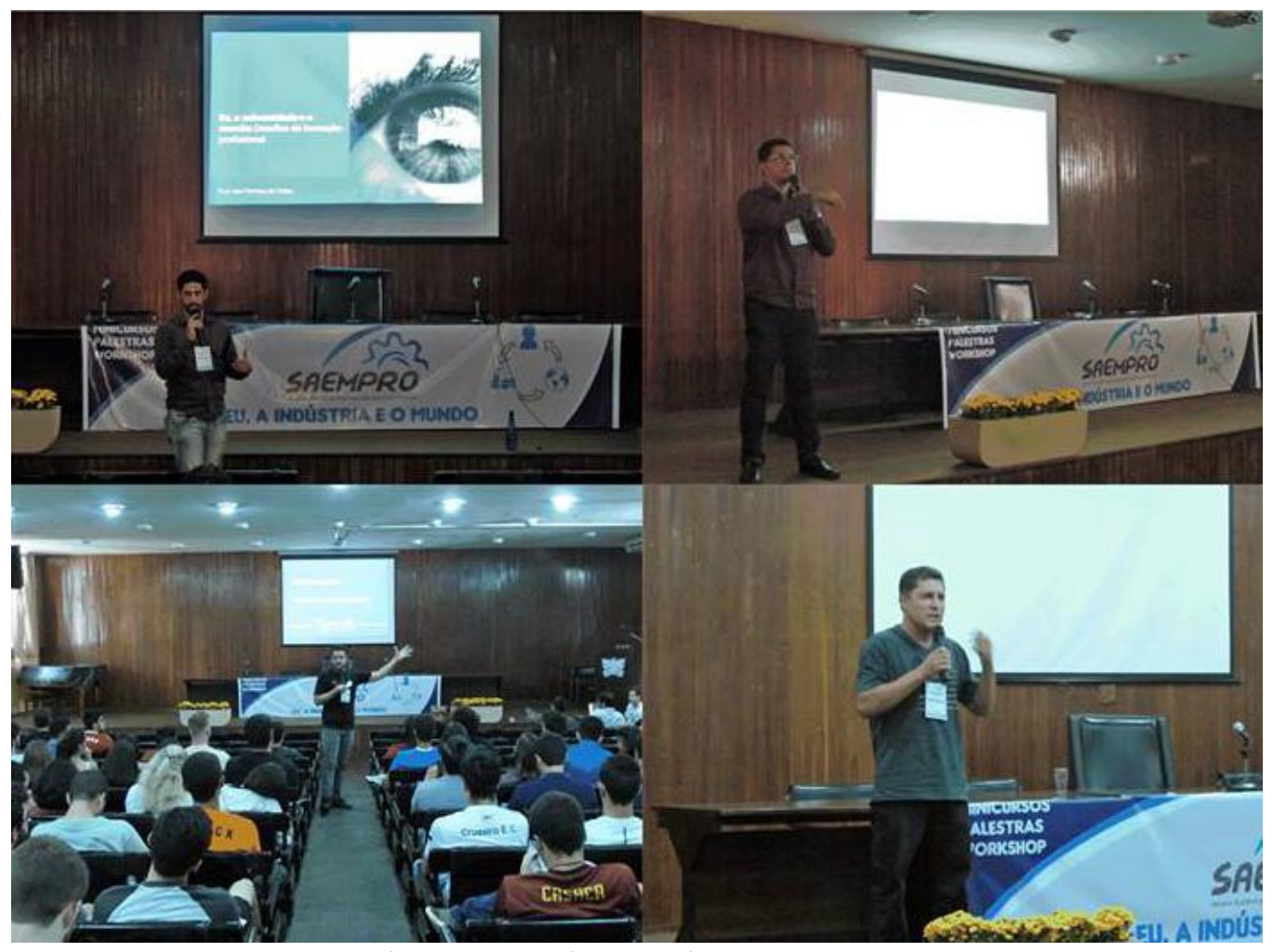

Figura 3 - Palestras da SAEMPRO 2016. 


\section{O DESAFIO SAEMPRO}

Durante o evento, foi promovido o "Desafio SAEMPRO 2016", que consistiu na resolução do seguinte case: Restaurante Universitário (RU) - UFV, conforme informações apresentadas na Figura 4.

Deste modo, as quatro equipes formadas por até quatro membros participantes da SAEMPRO puderam apresentar soluções para a problemática apresentada e foram avaliados com base nos seguintes critérios: adequação ao tema, criatividade, conteúdo, inovação, viabilidade e apresentação. Para avaliação das equipes, além de Professores de Departamento de Engenharia de Produção e Mecânica - DEP, participou também uma Professora do Departamento de Nutrição e Saúde - DNS, que também é a nutricionista responsável pelas refeições servidas no RU.

\footnotetext{
O Restaurante Universitário (RU) - UFV é um dos prédios mais utilizados pelos estudantes que frequentam a Universidade Federal de Viçosa. Localizado no Campus Viçosa, o restaurante oferece 4 refeições: café da manhã, almoço, lanche (jantar alternativo) e jantar; exceto nos finais de semana, quando são oferecidos apenas café da manhã e almoço.

Apesar dos inúmeros ajustes em sua capacidade de produção, o restaurante ainda apresenta alguns problemas e sofre com os diferentes picos de demanda no decorrer do ano. Entre as principais reclamações dos estudantes estão as longas filas enfrentadas em horários de intenso calor, as situações de pessoas que furam as filas e as porções de comida não padronizadas. Além disso, o refeitório permanece quente e abafado durante a maior parte das refeições, ocasionando mal-estar em quem frequenta o local. Outro ponto de bastante discordância, é a disposição dos carrinhos-de-alimentação que ocasionam diferentes fluxos no restaurante, o que dificulta a coleta das refeições e a devolução das bandejas.
}

Figura 4 - Desafio SAEMPRO 2016: case Restaurante Universitário (RU) - UFV.

Em suma, o RU apresenta 4 problemas fundamentais, que podem ser assim sistematizados:

$\checkmark \quad$ Filas longas e desorganizadas

$\checkmark \quad$ Pessoas que furam a fila

$\checkmark \quad$ Nã padronizaçao das porçoes

$\checkmark \quad$ Congestionamento dentro do RU

$\checkmark \quad$ Calor e abafamento

A proposta de solução apresentada por uma das equipes do Desafio SAEMPRO 2016 foi a seguinte: "Os problemas mais citados pelos alunos são: Filas grandes e desorganizadas enfrentadas em horário de intenso calor; A falta de padronização das porções de alimentos servidos; Ambiente quente e abafado. Para solucionar o problema da fila na parte externa, 
propomos que a fila seja guiada por um organizador de fila em fita retrátil (igual são nos aeroportos), assim impediríamos de haver furo de fila e as pessoas não ficariam mais no sol. Na parte interna haveria uma divisão do lugar onde o cliente se serve e do que ele entrega a bandeja, diminuindo as áreas de conflito e otimizando o tempo gasto na fila. Já para solucionar o problema da padronização das porções faríamos um controle de qualidade, pesando as carnes e sendo reprovadas as acima de uma massa X ou abaixo de uma massa $Y$. $O$ ambiente quente e abafado não seria mais realidade no $R U$ se trocassem os atuais exaustores, detalhe que mais da metade dos exaustores não funcionam, por exaustores solares, assim não só aumentando o fluxo de ar do refeitório, mas também economizando no gasto de energia elétrica, visto que o exaustor solar usa apenas a energia absorvida por suas placas fotovoltaicas."

Outra equipe apresentou as seguintes propostas de solução para os problemas identificados, que envolvem, as seguintes ações:

$\checkmark$ Organização da fila como em aeroportos: Ao invés de uma grade próxima à entrada de ambos os lados, uma fila com hastes de metal e fitas elásticas delimitando o caminho poderia aumentar a área utilizada ainda embaixo da cobertura e organizaria essa entrada ao restaurante. Os problemas amenizados seriam os "fura-filas", não se pode falar que isso acabaria, mas agora eles deveriam passar por baixo das fitas e não haveria as aglomerações no início da grade que são propícias a esse hábito, além disso a parcela da fila que estaria exposta ao sol e chuva poderia também diminuir, bem como as longas esperas, com a melhor organização;

$\checkmark$ Instituição do marmitex: essa solução tem como objetivo ajudar nos problemas de encontrar lugar para sentar e ter que almoçar em um ambiente abafado, os alunos que não teriam aulas à tarde e desejassem ir pra casa logo após o almoço, poderiam almoçar em casa, continuariam pagando um preço bem acessível, além de liberar espaço no RU para quem necessita de ficar na UFV após o almoço. Além disso, essa solução ajudaria no desperdício de comida, que não é exclusividade do $R U$, mas de qualquer restaurante, com o estudante levando a comida pra casa, essa não seria desperdiçada caso não fosse consumida na hora;

$\checkmark$ Plantio de árvores nos arredores: Árvores de médio a grande porte nos arredores auxiliariam na fila de espera quando o sol estiver radiando intensamente $e$ possivelmente fazendo sombra na própria edificação o problema da sensação térmica dentro durante o almoço poderia ser amenizado;

$\checkmark \quad$ Estender a cobertura: para ajudar no problema das filas no sol e chuva, a parte coberta poderia ser estendida;

$\checkmark$ "Treinamento": no que tange o as porções mal padronizadas, a solução pensada seria um melhor preparo dos profissionais que realizam o preenchimento das bandejas, já que a maioria dos alimentos são servidas com talheres ou recipientes próprios, não deveria haver tanta diferença entre as porções, já aquelas que são servidas com a mão, aos "punhados", deveriam ser feitas com utensilios, já que o número de repetições, bem como a pressa para servir causam essa não uniformidade;

$\checkmark \quad$ Venda de complementares: se ainda assim os usuários pensarem que certas quantidades de guarnições vêm em pequenas quantidades, poderia ser implantada a venda de complementares, em porções já prontas, por preços acessíveis, de mais carnes ou variedade da mesma, por exemplo. Isso também traria uma maior renda, e o preço base não precisaria ser acrescido, como vem sido discutido a tempos. 


\section{CONSIDERAÇÕES FINAIS}

A Semana Acadêmica de Engenharia Mecânica e de Produção - SAEMPRO 2016 teve como principal objetivo, um amplo debate sobre temas atuais de importância para a educação em engenharia mecânica e de produção e para o desenvolvimento de ações para o favorecimento da aproximação e da manutenção de contatos permanentes com a sociedade local e regional. O evento objetivou ainda disponibilizar espaço para difusão de conhecimentos científicos e experiências acadêmicas em ensino, pesquisa e extensão, produzidos em nível de graduação, reunindo estudantes, professores, pesquisadores e engenheiros. De maneira clara, a SAEMPRO 2016 alcançou o objetivo de estimular o interesse dos alunos participantes pelos cursos envolvidos, pelas suas linhas de pesquisa e mercado de trabalho dos profissionais de Engenharia Mecânica e de Produção. O evento também permitiu a interação entre alunos de todos os períodos dos cursos. Para aqueles estudantes envolvidos na organização, o evento foi uma oportunidade ímpar pela vivência de problemas, dificuldades e desafios e construção de oportunidades, soluções, relacionados ao campo de atuação dos engenheiros.

Em suma, a interação com diferentes tipos de conteúdo, tanto técnico como comportamental, foi um dos pilares da Semana Acadêmica de Engenharia Mecânica e de Produção - SAEMPRO 2016. Foi também uma oportunidade para os alunos apresentarem os trabalhos acadêmicos desenvolvidos.

\section{AGRADECIMENTOS}

Os autores agradecem a todos os professores e graduandos que contribuíram para o sucesso do evento, bem como aos ministrantes de minicursos ou palestras. Os autores agradecem ainda aos patrocinadores e apoiadores da SAEMPRO 2016.

\section{REFERÊNCIAS}

GONÇALVES, N. G. Indissociabilidade entre Ensino, Pesquisa e Extensão: um princípio necessário. Perspectiva, Florianópolis, v. 33, n. 3, p. 1229 - 1256, set./dez. 2015

MAZZILLI, S. Ensino, pesquisa e extensão: reconfiguração da universidade brasileira em tempos de redemocratização do Estado. RBPAE - v.27, n.2, p. 205-221, maio/ago. 2011.

MOITA, F. M. G. S. C., ANDRADE, F. C. B. Ensino-pesquisa-extensão: um exercício de indissociabilidade na pós-graduação. Revista Brasileira de Educação v. 14 n. 41 maio/ago. 2009.

PIVETTA, H. M. F. et al. Ensino, pesquisa e extensão universitária: em busca de uma integração efetiva. Linhas Críticas, Brasília, DF, v. 16, n. 31, p. 377-390, jul./dez. 2010,

SOARES, L. R., FARIAS, M .C. M., FARIAS, M. M., Ensino, pesquisa e extensão: histórico, abordagens, conceitos e considerações. Em Extensão, v. 9, N. 1, p. 11-18. 2010 . 


\title{
ACADEMIC WEEK OF MECHANICAL AND INDUSTRIAL ENGINEERING - SAEMPRO 2016
}

\author{
L. BENINI ${ }^{1}$, A. M. O. SIQUEIRA ${ }^{2}$ \\ ${ }^{1}$ Universidade Federal de Viçosa, Departamento de Engenharia de Produção e Mecânica \\ ${ }^{2}$ Universidade Federal de Viçosa, Departamento de Química \\ E-mail: lucas.benini@ufv.br
}

\begin{abstract}
The Academic Week of Mechanical and Industrial Engineering - SAEMPRO is an event organized by professors and students of the Mechanical Engineering and Industrial Engineering of Universidade Federal de Viçosa. SAEMPRO 2016 was supported by the Department of Mechanical and Industrial Engineering (DEP), the Academic Center of Industrial Engineering (DAEP) and the Industrial Engineering Tutorial Education Program (PET-EPR). This initiative is brought together in a single period and place a diverse set of activities, based on the teaching-research-extension tripod, which sought to stimulate the capacity for planning and project management by those involved, teachers and students. Allowed the interaction between students of all periods of the courses, as well as with graduates and specialized professionals. It was a great opportunity for students involved in the organization to have experiencing problems, difficulties and challenges and building opportunities, solutions, related to the field of action of the engineer.
\end{abstract}

KEYWORDS: Academic week; Engineering education; Mechanical Engineering; Industrial Engineering. 